\title{
Index to Dissertation Abstracts
}

\author{
BY CARL E. ORGREN
}

THIS NOTE is intended to facilitate the use of the indexes of Microfilm Abstracts and Dissertation Abstracts. The present title, Dissertation Abstracts, began with volume twelve.

1. The first eleven volumes, Microfilm Abstracts, are covered by a single cumulated author index, published by the Georgia Chapter of the Special Libraries Association in 1956. Approaching these first eleven volumes by subject is somewhat more difficult. The only subject lists available are cumulated tables of contents, arranged by broad topic, e.g.: chemistry; political science; literature, American. The following cumulations of these lists need to be searched to cover the first eleven volumes: Vol. 3 no. 2; Vol. 6 no. 2; Vol. 9 no. 3; Vol. 10 no. 4; Vol. 11 no. 4.

2. Volumes twelve through fifteen (Dissertation Abstracts) contain singleyear author and subject indexes at the end of each volume. The subject portion of these annual indexes is, again, a cumulation of the tables of contents of the separate numbers.

3. Beginning with volume sixteen (1956) Dissertation Abstracts took over the publication of the Index to American Doctoral Dissertations, an annual index to all American doctoral dissertations. The Index has an author index and an arrangement of subject headings somewhat finer than those used in Dissertation Abstracts, but it is not so detailed as those found in a standard dictionary catalog.

4. Volumes sixteen and seventeen of Dissertation Abstracts depend entirely upon the Index to American Doctoral Dissertations for their indexing. If a dissertation has been microfilmed and is abstracted in volume sixteen or seventeen
Mr. Orgren is Chief Reference Librarian in the University of Detroit.

of Dissertation Abstracts, its entry in the subject or author portions of Index to American Doctoral Dissertations will give its location in Dissertation Abstracts.

5. Volumes eighteen and nineteen of Dissertation Abstracts are covered by a separately published, cumulated, twoyear author index. For a subject approach to these volumes it is necessary to refer to the relevant volumes of Index to American Doctoral Dissertations. The method of such a subject search is indirect. The searcher first finds a dissertation in which he is interested in the subject entries of Index to American Doctoral Dissertations. This entry will give the author. The author's name is then checked in the cumulated author index to volumes eighteen and nineteen of Dissertations Abstracts to see if that particular dissertation was microfilmed and abstracted.

6. Volumes twenty and twenty-one of Dissertation Abstracts have single volume author indexes at the end of each volume. Subject searches are done, again, by using the corresponding volumes of the Index to American Doctoral Dissertations.

7. Beginning with volume twenty-two of Dissertation Abstracts a new policy has been followed. A subject index appears in each number along with the usual author index. At the end of the volume (no. 12, Part II) these are cumulated. These cumulated volume indexes include for the first time a true subject index. The subject headings are basically 


\section{SUBJECT INDEXES}

$\begin{array}{ccl}\text { Volume } & \text { Number } & \\ 3 & 2 & \\ 6 & 2 & \\ 9 & 3 & \\ 10 & 4 & \\ 11 & 4 & \\ 12 & 6 & \\ 13 & 6 & \\ 14 & 12 & \\ 15 & 12 & \\ 16 & 13 & \text { Index to American Doctoral Dissertations 1955-56 } \\ 17 & 13 & \text { Index to American Doctoral Dissertations 1956-57 } \\ 18 & 7 & \text { Index to American Doctoral Dissertations 1957-58 } \\ 19 & 13 & \text { Index to American Doctoral Dissertations 1958-59 } \\ 20 & 13 & \text { Index to American Doctoral Dissertations 1959-60 } \\ 21 & 13 & \text { Index to American Doctoral Dissertations 1960-61 } \\ 22 & 12 & \text { Part II } \\ 23 & 12 & \text { Part II }\end{array}$

AUTHOR INDEXES

\begin{tabular}{|c|c|c|}
\hline Volume & Number & \\
\hline $1-11$ & & cumulated author index \\
\hline 12 & & \\
\hline 13 & 6 & \\
\hline 14 & 12 & \\
\hline 15 & 12 & \\
\hline 16 & 13 & Index to American Doctoral Dissertations $1955-56$ \\
\hline 17 & 13 & Index to American Doctoral Dissertations $1956-57$ \\
\hline $18-19$ & & cumulated author index \\
\hline 20 & 12 & Part II \\
\hline 21 & & Vol. 22 no. 5 , usually bound at end of Vol. 21 \\
\hline 22 & 12 & Part II \\
\hline 23 & 12 & Part II \\
\hline
\end{tabular}

those of the Library of Congress and so are familiar to many users.

The information thus far contained in this note may be assembled in tabular form for convenience in searching:

Such a search can be simplified by the use of colored tabs. The above index volumes may be tabbed in red, including the volumes of Index to American Doctoral Dissertations which serve as indexes to Dissertation Abstracts. All volumes of Index to American Doctoral Dissertations may be tabbed in green.
Index to American Doctoral Dissertations has been treated here chiefly as it concerns the indexing of Dissertation $A b$ stracts. It is necessary to point out that it is an important service in its own right. It is not limited to the listing of microfilmed dissertations as is Dissertation $\mathrm{Ab}$ stracts. It is a more complete list of American doctoral dissertations, and so is the first place to look if only basic bibliographical information of the dissertation is needed. 